\title{
ARTICLE
}

\section{Results of quantitative and qualitative analyses of traditional prescription "Lonlunsemberu-13"}

Nyamdemberel Tsagaanbaatar* and Chimedragchaa Chimedtseren

Institute of Traditional Medicine and Technology Ulaanbaatar, Mongolia

ARTICLE INFO: Received: 09 Dec, 2019; Accepted: 15 Jun, 2020

\begin{abstract}
Traditional prescription Lonlunsemberu-13 has been widely used in traditional Mongolian medicine to treat gastro intestinal dyspepsia.

The purpose of this study was to determine biologically active substances in the Traditional prescription Lonlunsemberu-13 as a primary research.

We screened for phenolic compounds, flavonoids, coumarins and alkaloids using a TLC method, and then we have determined those biologically active substances content by the UV/Vis spectrophotometric method. We identified the gallic acid, rutin, quercetin, apigenin, luteolin, isofraxidin and piperine in the traditional prescription. The result revealed that "Lonlunsemberu13 " consisted $4.38 \% \pm 1.9$ of total phenolic compounds, $0.63 \% \pm 0.17$ flavonoids, $2.45 \% \pm 0.28$ of coumarins and $0.83 \% \pm 0.064$ alkaloids.
\end{abstract}

Keywords: Lonlunsemberu-13; thin layer chromatography; UV/Visible spectrophotometer; polyphenolics; flavonoid; coumarin; alkaloid;

\section{INTRODUCTION}

Traditional medicine has always played an important role in Mongolia's medicinal science. It continues to be practiced widely, supplying health-care needs of a large portion of the population. Folk medicine, based on the experiences of nomadic people, has its own unique medical theory, techniques and medications. Some aspects of Mongolian folk medicine along with elements from other Asian systems, such as Tibetan medicine, Ayurveda and traditional Chinese medicine have been integrated into the Mongolian medical system.

Traditional medicine practices and knowledge, including the use of medicinal plants, have been passed down from one generation to another via oral traditions.

Today, throughout the world there is intensive activity related to traditional medicine, ranging from extensive research into different plant species to their therapeutic application.

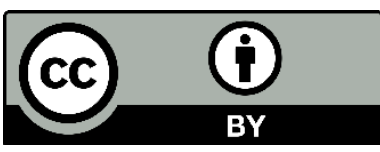

The Author(s). 2020 Open access This article is distributed under the terms of the Creative Commons Attribution 4.0 International License (https://creativecommons.org/licenses/by/4.0/), which permits unrestricted use, distribution, and reproduction in any medium, provided you give appropriate credit to the original author(s) and the source, provide a link to the Creative Commons license, and indicate if changes were made. 
The strong interest in traditional medicine, especially in naturally occurred and herbal medicine, is growing across the world. In Mongolian flora, about 860 from 2860 plant species were defined as having medicinal properties. Drugs with different properties can be developed based on broad pharmacological activities of flavonoids, alkaloids, coumarins, sesquiterpenoids and other biologically active compounds contained in plants. Mongolian scientists have conducted primary and advanced phytochemical research by using some 150 medicinal plants and herbs, which have been used in traditional Mongolian medicine $[4,6]$.

As recorded in traditional medical sources, "Lonlunsemberu-13" has been widely

\section{MATERIALS AND METHODS}

\section{Standards and Chemicals:}

Folin-Ciocalteu reagent from Sangon (China), gallic acid, rutin, isofraxedin and piperine were acquired from Sigma Aldrich (USA). All other solvents and chemicals were of analytical grade.

The study was carried out in the Institute of Traditional Medicine and Technology of Mongolia. The "Lonlunsemberu-13" prescription was produced in the Traditional Medicinal Drug Factory of the Institute of Traditional Medicine. Biologically active compounds of the "Lonlunsemberu-13" prescription were studied by using UV/Vis spectrophotometry and TLC methods.

\section{TLC identification of biologically active substances}

Sample preparation: $0.5 \mathrm{~g}$ of samples was extracted in $10 \mathrm{~mL} 70 \%$ ethanol for $24 \mathrm{~h}$, filtered and the filtrate was used as a test solution.

Identification of total phenolic compounds: Standard gallic acid substance was dissolved in $70 \%$ ethanol to produce a solution containing $4 \mathrm{mg}$ per $\mathrm{ml}$ as the reference solution. The method for TLC was applied, using silica gel $60 \mathrm{~F}_{254}$ (Merck, Germany) plates as the coating substance and a mixture of benzene: ethyl acetate: formic acid: acetone 5:5:2:0.5 as the mobile phase. After the used in traditional Mongolian medicine to treat dyspepsia-gastrointestinal disorders.

"Lonlunsemberu-13" is composed of 13 medicinal herbs, including Amomum kravanh Pire ex gagner., Amomum tsao Ko Grevost et Lemaire., Terminalia chebula Retz., Alpinia officinarum Hance., Carthamus tinctorus L., Piper longum L., Piper nigrum L., Myristica fragrans Houtt., Purica granatum L., Cinnamomum cassia Pres., Nigella glandulifera., Halite and Halit violace [2, 4]. These medicinal herbs contain bio-active compounds, such as flavonoids, coumarins, phenolic compounds, alkaloids and essential oil $[3,5,7,8,14]$.

development and removal of the plate, it was dried in air. It was sprayed with a $2 \%$ iron trichloride in ethanol and heated at $100-105^{\circ} \mathrm{C}$ $[3,9,11,13]$.

Identification of flavonoids: Standard rutin, quercetin, apigenin and luteolin substances were dissolved in $70 \%$ ethanol to produce a solution containing $4 \mathrm{mg}$ per $\mathrm{ml}$ as the reference solution. The TLC method was applied using silica gel $60 \mathrm{~F}_{254}$ plates as the coating substance and a mixture of toluene: ethyl: acetate: acetic acid- 4.5:5:0.5 and ethylacetate: acetic acid: formic acid: water 100:11:11:26 as the mobile phase. After the development and removal of the plate, it was dried in air, and sprayed with a $3 \%$ ammonium chloride in ethanol $[9,11,13]$.

Identification of coumarins: Standard isofraxedin substance was dissolved in $70 \%$ ethanol to produce a solution containing $4 \mathrm{mg}$ per $\mathrm{ml}$ as the reference solution. The TLC method was applied using silica gel $60 \quad \mathrm{~F}_{254}$ plates as the coating substance and a mixture of toluene: ethyl acetate: acetic acid - 4.5:5:0.5 as the mobile phase. After development and removal of the plate, it was dried in air and sprayed with a $10 \%$ potassium hydroxide in ethanol $[9,10,13]$.

Identification of alkaloids: Standard piperine substance was dissolved in $70 \%$ ethanol to produce a solution containing $4 \mathrm{mg}$ 
per $\mathrm{ml}$ as the reference solution. TLC method was applied using plates as the coating substance and a mixture of toluene: acetone: methanol: ammonia - 49.5:41.5:8:5 as the mobile phase. After development and removal of the plate, it was dried in air and sprayed with a Dradendorff's reagent $[10,11,13]$.

\section{Quantitative UV/Vis spectrophotometric determination}

Sample preparation: $0.5 \mathrm{~g}$ drug was extracted in $50 \mathrm{~mL} 70 \%$ ethanol solvent. After the extraction, the sample was filtered and the filtrate was transferred to a $50 \mathrm{~mL}$ volumetric flask, and to which $70 \%$ ethanol was added to facilitate sample extract (A solution).

Determination of total phenolic compounds content: The total content of phenolic compounds was determined spectrophotometrically by using a FolinChiocalteu reagent, which resulted in a dark blue complex compound.

Solution A $5 \mathrm{~mL}$ was transferred to a 25 $\mathrm{mL}$ volumetric flask, and diluted with $70 \%$ ethanol to the volume (B solution).

$0.5 \mathrm{~mL}$ of solution $\mathrm{B}$ was transferred to a $25 \mathrm{~mL}$ volumetric flask containing distilled water $(10 \mathrm{~mL})$ and Folin Ciocalteu reagent $(1$ $\mathrm{mL}$ diluted tenfold). The solution was diluted with $10.75 \%$ sodium carbonate $(\mathrm{w} / \mathrm{v})$. The absorbance of the blue solution was measured after 30 minutes at room temperature at $760 \mathrm{~nm}$ in UV-Visible spectrophotometer - 1601 (Shimadzu, Japan) $[1,12]$. Distilled water was used as a blank.

\section{Preparation of standard solution for calibration curve of gallic acid}

$15 \mathrm{mg}$ of gallic acid reference substance, with constant weight, is weighed precisely and put into $50 \mathrm{~mL}$ volumetric flask with a small amount of distilled water and then diluted to the volume. It was shaken well, put aside. The exact amount is taken from solution 1, 3, 5, 7 and $9 \mathrm{~mL}$ placed in $25 \mathrm{~mL}$ volumetric flasks, respectively, and diluted to the volume. The final concentrations were 12, 36, 60, 84 and 108 $\mu \mathrm{g} / \mathrm{mL}$ of galllic acid. Then, a mixture was prepared with $0.5 \mathrm{~mL}$ of this each stock solution, $1 \mathrm{~mL}$ Folin-Ciocalteu reagent, and 10 $\mathrm{mL}$ of water, and volumetrically diluted to 25
$\mathrm{mL}$ with $10.75 \%$ sodium carbonate $(\mathrm{w} / \mathrm{v})$. After $30 \mathrm{~min}$, the absorbance was measured at 760 $\mathrm{nm}$, using water as the compensation liquid and quartz cell ( $1 \mathrm{~cm}$ path length) in a UV/Vis spectrophotometer.

Determination of total flavonoid content: $3 \mathrm{~mL}$ of solution A was transferred to a $25 \mathrm{~mL}$ volumetric flask containing distilled water $(6 \mathrm{~mL})$ and $5 \%$ NANO2 $(1 \mathrm{~mL})$. After standing for 6 minutes, $10 \% \mathrm{AlCl} 3$ solution $(1 \mathrm{~mL})$ and $4 \% \mathrm{NaOH}(10 \mathrm{~mL})$ were added and then diluted with distilled water to the volume. The absorbance of the red colored solution was measured after $15 \mathrm{~min}$ at room temperature at $500 \mathrm{~nm}$ in UV/Vis spectrophotometer-1601 (Shimadzu, Japan) [1, 10]. 70\% ethanol was used as a blank.

\section{Preparation of standard solution for calibration curve of rutin}

$10 \mathrm{mg}$ of rutin reference with constant weight is weighed precisely and put into $50 \mathrm{~mL}$ volumetric flask with a small amount of $70 \%$ ethanol and then diluted to the volume. It was shaken well and put aside. The exact amount is taken from solution $0.5,1,2,3,4$ and $5 \mathrm{~mL}$ placed in $25 \mathrm{~mL}$ volumetric flasks, respectively, and added with distilled water $(3 \mathrm{~mL})$ and $5 \%$ $\mathrm{NANO}_{2}(1 \mathrm{~mL})$. After standing for 6 minutes, it was combined with $10 \% \mathrm{AlCl} 3$ solution $(1 \mathrm{~mL})$, $4 \% \mathrm{NaOH}(10 \mathrm{~mL})$ and diluted with distilled water to the volume. The final concentrations were $4,8,16,24,32$ and $40 \mu \mathrm{g} / \mathrm{mL}$ of rutin. After $15 \mathrm{~min}$, the absorbance was measured at $500 \mathrm{~nm}$, in a UV/Vis spectrophotometer. 70\% ethanol was used as a blank.

Determination of total coumarin content: $1 \mathrm{~mL}$ of solution A was transferred to a $25 \mathrm{~mL}$ volumetric flask diluted with $70 \%$ ethanol to the volume. The absorbance solution was measured after $15 \mathrm{~min}$ at room temperature at $336 \mathrm{~nm}$ in UV/Vis spectrophotometer-1601 (Shimadzu, Japan) [8, 14]. 70\% ethanol was used as a blank.

\section{Preparation of standard solution for calibration curve of isofraxedin}

$2 \mathrm{mg}$ of isofraxedin reference substance with a constant weight is weighed precisely and put into $10 \mathrm{~mL}$ volumetric flask with small amount of $70 \%$ ethanol and then diluted to the 
volume. It was shaken well and kept aside. The exact amount is taken from solution 1.5, 2, 2.5, and $3 \mathrm{~mL}$ is placed in $10 \mathrm{~mL}$ volumetric flasks respectively and diluted to the volume. The final concentrations were $30,40,50$ and 60 $\mu \mathrm{g} / \mathrm{mL}$ of isofraxedin. After $15 \mathrm{~min}$, the absorbance was measured at $336 \mathrm{~nm}$, in a $\mathrm{UV} / \mathrm{V}$ is spectrophotometer. $70 \%$ ethanol was used as a blank.

Determination of total alkaloid content: $1 \mathrm{~mL}$ solution A was transferred to a $25 \mathrm{~mL}$ volumetric flask diluted with $70 \%$ ethanol to the volume. The absorbance solution was measured after $15 \mathrm{~min}$ at room temperature at $343 \mathrm{~nm}$ in UV/Vis spectrophotometer-1601 (Shimadzu, Japan) [5, 7,12]. 70\% ethanol was used as a blank.

\section{RESULTS AND DISCUSSION}

The results of qualitative analysis of "Lonlunsemberu-13" are shown in Table 1 and quantitative analyses summarized in Table 2.

TLC results - total phenolic compounds (gallic acid), flavonoids (rutin, quercetin, apigenin, luteolin), coumarins (isofraxedin) and alkaloids (piperine) were identified in "Lonlunsemberu-13".

Gallic acid was identified in the solvent system benzene-ethylacetate-formic acidacetone $(5: 5: 2: 0.5)$. It was dark-blue in color, $\mathrm{Rf}=0.88$, on TLC plate.

Rutin, apigenin, luteolin and quercetin aglycones of flavonoid was identified in the solvent system toluone-ethylacetate-acetic acid (4.5:5:0.5) and ethylacetate - acetic acid formic acid - water (100:11:11:26), which showed yellow and yellow fluorescence color; Rf values were $0.6,0.82,0.9$ and 0.78 respectively. Also, Isofraxedin and piperine were identified in the solvent system toluene - ethylacetate - acetic acid (4.5:5:0.5) and toluene - acetone - methanol - ammonia (49.5:41.5:8:5). It showed blue fluorescence and orange color, $\mathrm{Rf}$ values were 0.61 and 0.85 respectively (Table 1).

These biologically active substances were contained in the components of raw materials of traditional prescription "Lonlonsemberu$13 "$ ".

\section{Preparation of standard solution for calibration curve of alkaloid}

$1 \mathrm{mg}$ piperine reference substance with constant weight is weighed precisely and put into $50 \mathrm{~mL}$ volumetric flask with small amount of $96 \%$ ethanol and then diluted to the volume. It was shaken well and kept aside. The exact amount is taken from solution 1, 2, 4, 6, 8 and $10 \mathrm{~mL}$ placed in $10 \mathrm{~mL}$ volumetric flasks respectively and diluted to the volume. The final concentrations were 2, 4, 8, 12, 16 and 20 $\mu \mathrm{g} / \mathrm{mL}$ of piperine. After $15 \mathrm{~min}$, the absorbance was measured at $343 \mathrm{~nm}$, in a $\mathrm{UV} / \mathrm{Vis}$ spectrophotometer. $96 \%$ ethanol was used as a blank [5].

The researchers determined that plants, such as Terminalia chebula Retz., Purica granatum L., Carthamus tinctorus L., Amomum kravanh Pire ex gagner., Alpinia officinarum Hance., Cinnamomum cassia Pres, Piper longum L. and Piper nigrum L contained gallic acid, ellagic acid, tannic acid, ethyl gallate, chebulic acid, chebulagic acid, corilagin, mannitol, ascorbic acid, coumarins, flavonoids as a polyphenolic compounds and piperine, piperidine, trimethoxy cinnamoyl-piperidine, piperlongumine as alkaloids $[5,12,14]$.

As a result of quantitative analysis, we determined the content of biologically active substances in traditional prescription, such as phenolic compounds, flavonoids, coumarins, and alkaloids, by using UV/Vis spectrophotometric method respectively.

The calibration curve of standard gallic acid, rutin, isofraxedin for the estimation of total phenolic, total flavonoids and total coumarins has been shown in Fig 2, 3, 4. While calibration curve of standard piperine for the quantification of total alkaloids has been shown Figure 5.

As shown in Figure 2, the result indicated gallic acid had linear relationship with peak area in the concentration range $12-108 \mu \mathrm{g} / \mathrm{mL}$, calibration equation $\mathrm{y}=110.77 \mathrm{x}-0.0736\left(\mathrm{r}^{2}=\right.$ 09917). The RSD of gallic acid peak area was $4.2 \%(\mathrm{n}=5)$. 
Table 1. Identification of bio-active compounds in sample

\begin{tabular}{|c|c|c|c|c|}
\hline & Solvent system & Identification reagent & $\begin{array}{c}\text { Color, after } \\
\text { detection }\end{array}$ & $\begin{array}{c}\mathbf{R}_{\mathbf{f}} \\
\text { value }\end{array}$ \\
\hline 1 & $\begin{array}{l}\text { benzene-ethylacetate-formic acid- } \\
\text { acetone (5:5:2:0.5) }\end{array}$ & $\begin{array}{c}2 \% \mathrm{FeCl}_{3} \\
\text { Heating }\left(100^{\circ} \mathrm{C}\right) \\
\text { Visible light }\end{array}$ & Dark-blue & 0.88-Gallic acid \\
\hline 2 & $\begin{array}{l}\text { Toluone-ethylacetate-acetic acid } \\
\text { (4.5:5:0.5) }\end{array}$ & \multirow[t]{2}{*}{$\begin{array}{l}\text { 3\% } \mathrm{AlCI}_{3} \\
\mathrm{UV}_{365} \text { light }\end{array}$} & Yellow & $\begin{array}{c}0.6 \text { - Rutin } \\
\text { 0.82-Apigenin } \\
0.9 \text {-Luteolin }\end{array}$ \\
\hline 3 & $\begin{array}{l}\text { Ethylacetate- acetic acid- formic } \\
\text { acid-water (100:11:11:26) }\end{array}$ & & $\begin{array}{c}\text { Yellow } \\
\text { fluorescence }\end{array}$ & 0.78-Quercetin \\
\hline 4 & $\begin{array}{c}\text { Toluone- ethylacetate-acetic acid } \\
(4.5: 5: 0.5)\end{array}$ & $\begin{array}{l}10 \% \mathrm{KOH} \\
\mathrm{UV}_{365} \text { light }\end{array}$ & Blue fluorescence & 0.61-Isofraxedin \\
\hline 5 & $\begin{array}{l}\text { Toluone- acetone-methanol- } \\
\text { ammonia (49.5:41.5:8:5) }\end{array}$ & $\begin{array}{l}\text { Dragendorff's reagent } \\
\text { Visible light }\end{array}$ & Orange & 0.85-Piperine \\
\hline
\end{tabular}

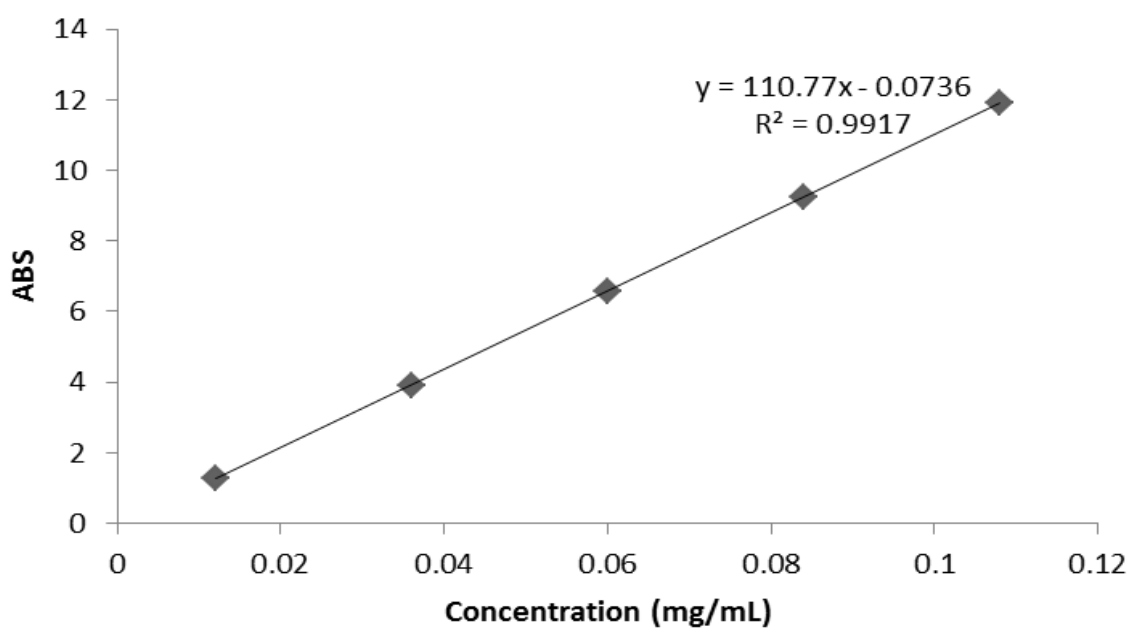

Figure 1. Gallic acid calibration curve

A good linear relationship was observed between absorbance and concentration of rutin in the concentration range $4-40 \mu \mathrm{g} / \mathrm{mL}$, regression value of $\mathrm{r}^{2}=09999$, calibration equation $\mathrm{y}=0.0955 \mathrm{x}-0.0008$. The RSD was $0.16 \%(n=6)$.

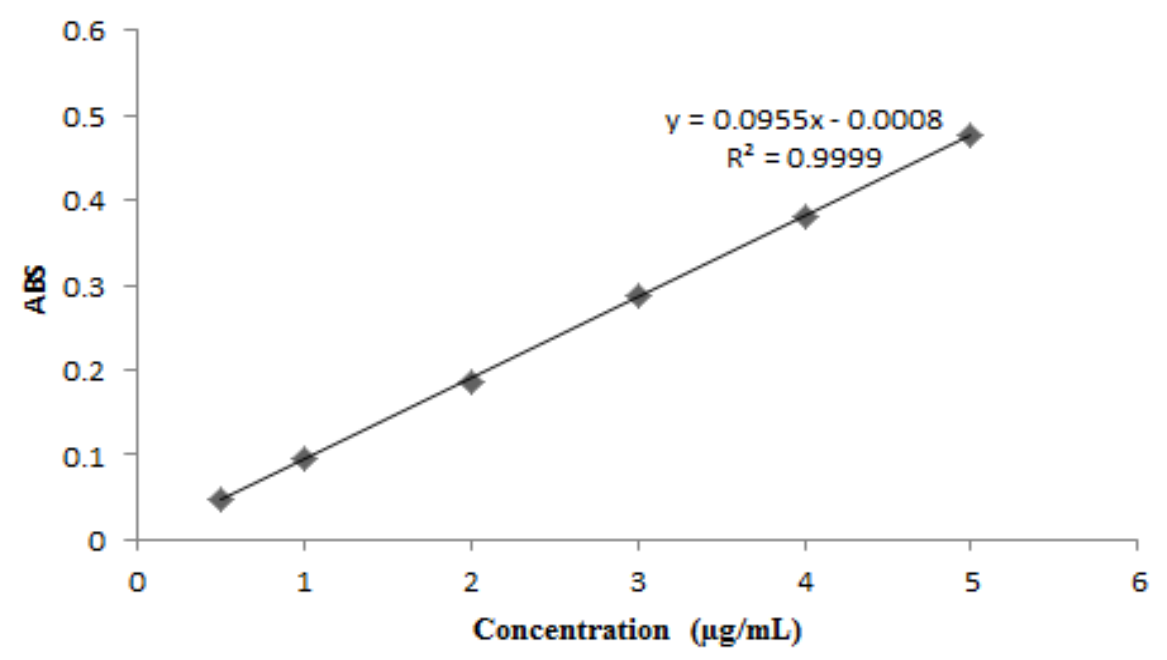

Figure 2. Rutin calibration curve 
The isofraxedin in the concentration range was $30-60 \mu \mathrm{g} / \mathrm{mL}$, the calibration equation $\mathrm{y}=0.0653 \mathrm{x}+0.0019$, with $\mathrm{a}$ regression value of $r^{2}=0.9990$. The RSD was $0.84 \%(n=4)$.

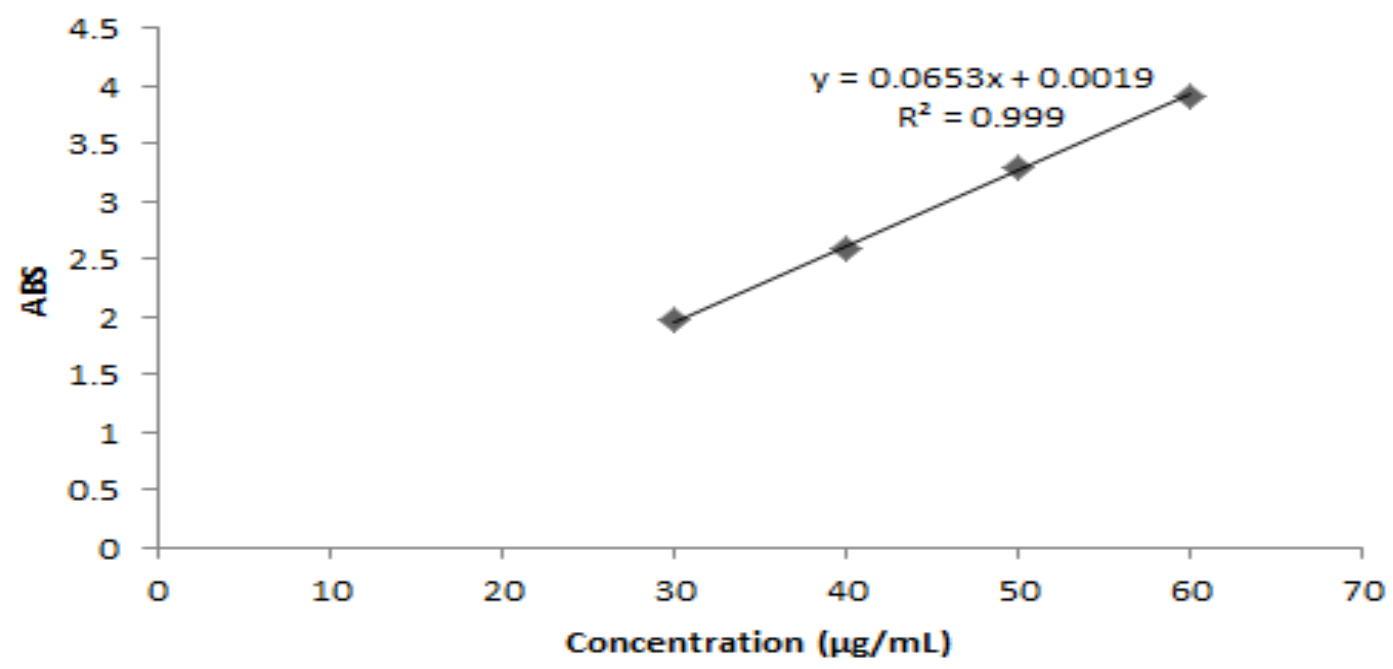

Figure 3. Isofraxedin calibration curve

Also, while for piperine in the range 2-20 $\mu \mathrm{g} / \mathrm{mL}$, the calibration equation $\mathrm{y}=0.0793 \mathrm{x}-$
0.0818 , regression value of $\mathrm{r}^{2}=0.9962$. The RSD was $0.55 \%(n=6)$

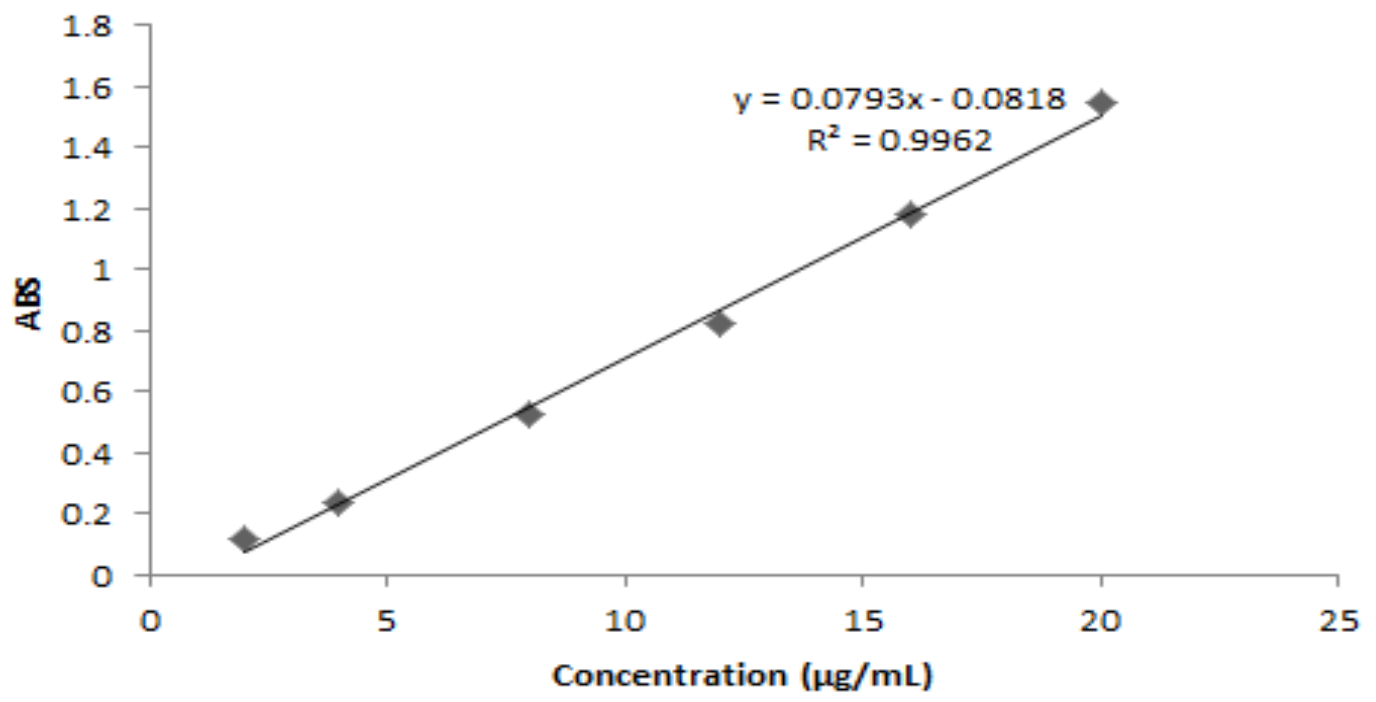

Figure 4. Piperine calibration curve

All the calibration graphs showed strong positive linear correlation ( $\mathrm{r}$ ), which is close to +1 . Thus, the content of total phenolic compounds, flavonoids, coumarins and alkaloids in traditional prescription was calculated by the formula of linear equation of the above standard substances were shown in figure 1, 2, 3 and 4 respectively. The results are summarized in table 2. 
Table 2. Contents bio-active substances

\begin{tabular}{|c|c|c|c|}
\hline № & Biologically active substances & Values obtained (\%) & Average $(\%)$ \\
\hline \multirow{3}{*}{1} & \multirow{3}{*}{ Total phenolics } & 6.58 & \multirow{3}{*}{$4.38 \pm 1.9$} \\
\hline & & 2.97 & \\
\hline & & 3.61 & \\
\hline \multirow{3}{*}{2} & \multirow{3}{*}{ Total flavonoids } & 0.74 & \multirow{3}{*}{$0.63 \pm 0.17$} \\
\hline & & 0.72 & \\
\hline & & 0.43 & \\
\hline \multirow{3}{*}{3} & \multirow{3}{*}{ Total coumarins } & 2.32 & \multirow{3}{*}{$2.45 \pm 0.28$} \\
\hline & & 2.26 & \\
\hline & & 2.78 & \\
\hline \multirow{3}{*}{4} & \multirow{3}{*}{ Total alkaloids } & 0.82 & \multirow{3}{*}{$0.83 \pm 0.06$} \\
\hline & & 0.90 & \\
\hline & & 0.77 & \\
\hline
\end{tabular}

The "Lonlunsemberu-13" contained high levels of total phenolic compounds $(4.38 \%$ \pm 1.9 ). The total flavonoids, coumarins and alkaloids content in prescription were found to be $0.63 \% \pm 0.17,2.45 \% \pm 0.28$ and $0.83 \%$ \pm 0.064 respectively.

Phenolic compounds are believed to have some favorable effects on human health such as

\section{CONCLUSIONS}

It can be concluded from the present study that the "Lonlunsemberu-13" prescription possesses various phytochemicals like total phenolic compounds, flavonoids, coumarins and alkaloids in high quantity. These phytochemicals possess various bioactive properties.

Therefore, it is important to understand the mechanism of action of treatment in relation lowering of the human low-density lipoprotein, reduction of heart diseases and cancer. Antioxidant compounds include vitamins, carotenoids, flavonoids and phenolic. Among them, phenolic compounds and flavonoids are the most important, and exhibit substantial antioxidant activity.

to these biologically active substances in traditional prescription.

We are now trying to identify and determinate the different phytochemicals from the traditional prescription.

\section{Acknowledgements}

The study was supported by the Institute of Traditional Medicine and Technology of Mongolia's Traditional Medicinal Drug Factory.

\section{REFERENCES}

1. Anna Pekal., Krystyna Pyrzynska. (2014) Evaluation of Aluminium Complexation reaction for Flavonoid Content Assay. Food Anal. Methods, Springer (2014). DOI:10.1007/s12161-014-9814, 7: pp. 1776-1782.

2. Chimedchagraa Ch., Dagvatseren B., Khishigjargal L., et all. (2015) Reference Book of Control of Traditional Medicinal

compress. p. 294

3. Chinese pharmacopoeia commission Pharmacopoeia of the People's Republic of China. Vol 1: People's Medical Publishing House; 2005.

4. Dagvatseren B., Khishigjargal L., Narantsetseg D., (2014) Reference Book of Traditional Medicines and Herbal Materials. Ulaanbaatar. Admon. P. 64. 
5. Maitreyi Zaveri, Amit Khandhar, Samir Patel, Archita Patel. Chemistry and pharmacology of Piper longum $l$. International Journal of Pharmaceutical Sciences Review and Research Volume 5, Issue 1, November-December 2010; Article-010.

6. Medicinal Plants in Mongolia. (2013). World Health Organization Regional Office for Western Pacific.

7. Narendra Kumar Singh., Pramod Kumar et all. (2011) UV-spectrophotometric method development for estimation of piperine in Chitrakadi Vati. Scholars Research Library., ISSN 0975-5071, 3(3): pp. 178182.

8. Nur Syaida binti Yusof. Phytochemical studies and biological activity of cinnamomum microphyllum. (21962) Bachelor of Science with Honours (Resource Chemistry) 2012. pp. 3-9.

9. Pharmacopoeia of the People's Republic of China. (2010), Chinese pharmacopoeia Commission. China Medical Science Press. Vol 1: pp. 27, 89, 100, 291, 335.
10. Preeti Tiwari. (2014) Phenolic and Flavonoids and Antioxidant Potential of Balarishta Prepared by Traditional and Modern Methods. Asian J. Pharm.Ana.; Vol. 4: Issue 1, pp. 05-10.

11. Tensingh N Baliah., Astalakshmi A. Phytochemical analysis and antibacterial activity of extracts from Terminalia chebula Retz. Int.J.Curr.Microbiol.App.Sci (2014) 3(3): pp.992-999.

12. Trivedi $\mathrm{M} \mathrm{N}$ et al. Pharmacognostic, phytochemical analysis and antimicrobial activity of two piper species. Pharmacie Globale (IJCP) 2011, 7 (05). pp. 1-5.

13. Wagner H., Bladt S. (1996) Plant drug analysis. A Thin Layer Chromatography atlas. Second edition. Springer-Verlag. Berlin. Pp. 4, 126, 196.

14. Wei Zhao., Yueping Ma., Zhong Yuan. (2012). Optimization of extraction method for the polyphenols from twigs of Cinnamomum cassia. Asian Journal of Traditional Medicines., ISSN 1817-4337, Vol.7 (6): pp. 256-258. 